day of testing compared with the first was determined, and chi-square tests were performed comparing animals whose scores declined with those whose scores increased. The result was significant for light-tested rats $\left(\chi^{2}=5.54\right.$, $\mathrm{p}<.02$ ), but not for dark-tested animals.

The slightly greater horizontal activity of the darktested animals, seen in the descriptive measures but not in the inferential tests, provides a modicum of support for the greater locomotor activity in the dark reported by Richter (1965). The lack of evidence for habituation in the dark-tested animals provides further support for an enhanced exploratory tendency during the dark portion of the cycle.

\section{Vertical Activity}

An overall comparison of 5-day rearing scores of animals tested in the light vs. those tested in the dark was significant $[t(53)=3.04, p<.01]$. For each test period, the 5-day totals for dark-tested rats were lower than those for light-tested animals, but the only statistically significant difference was for animals tested at $12: 30$ p.m. $[t(17)=2.45, p<.05]$. Time of testing in either the dark or the light was not a factor in the vertical activity scores.

It is difficult to account for the greater rearing activity seen in the light-tested rats. One possible explanation might be that there is an inverse relationship between horizontal activity and rearing. That is, the slightly greater horizontal activity noted in dark-tested subjects was associated with slightly less vertical activity, whereas the opposite result was seen in the light-tested animals.

Unfortunately for this thesis, the correlations between horizontal and vertical activity for dark-tested and light- tested rats were found to be positive. In fact, the relationship for the light-tested animals was significant $(\mathrm{r}=.503, \mathrm{p}<.01)$

\section{REFERENCES}

Hery, F., Rouer, E., \& Glowinski, J. Daily variations of serotonin metabolism in the rat brain. Brain Research, 1972, 43, 445-465.

Kane, N. L., \& KnUtson, J. F. Influence of colony lighting conditions on home-cage spontaneous aggression. Journal of Comparative and Physiological Psychology, 1976, 90, 889-897.

Knutson, J. F., Hynan, M. T., \& Kane, N. L. Influence of home-cage lighting conditions on shock-induced fighting. Journal of Comparative and Physiological Psychology, 1976, $90,877-888$.

MaLick, J. B. Effects of age and food deprivation on the development of muricidal behavior in rats. Physiology \& Behavior, 1975, 14, 171-175.

MOYER, K. E. Kinds of aggression and their physiological basis. Communications in Behavioral Biology, 1968, 2, 65-87.

Paul, L., Miley, W. M., \& Baenninger, R. Mouse killing by rats: Roles of hunger and thirst in its initiation and maintenance. Journal of Comparative and Physiological Psychology, 1971, 76, 242-249.

RAGER, K. B., \& Thorne, B. M. The effects of food deprivation and the length of the test on muricide in rats. Physiology \& Behavior, 1977, 18, 759-762.

RiChte R, C. P. Biological clocks in medicine and psychiatry. Springfield, Ill: Thomas, 1965.

Thorne, B. M., Aaron, M., \& Latham, E. E. Effects of olfactory bulb ablation upon emotionality and muricidal behavior in four rat strains. Journal of Comparative and Physiological Psychology, 1973, 84, 339-344.

Thorne, B. M., \& Hutton, B. The effects of food deprivation and the time of the test on muricide in the Long-Evans rat. Bulletin of the Psychonomic Society, 1978, 6, 307-308.

ZuCKER, I. Light-dark rhythms in rat eating and drinking behavior. Physiology \& Behavior, 1971, 6, 115-126.

(Received for publication January 12, 1981.)

\title{
ERRATUM
}

Fanselow, M. S. Extinction of contextual fear and preference for signaled shock. Bulletin of the Psychonomic Society, 1980, 16(6), 458-460. Page 459, Column 2, Paragraph 2, Lines 5-8, the sentence should read: The experimental animals spent $60 \%$ of their time on the signaled side, significantly less than the controls, which spent $84 \%$ of their time on the signaled side $[\mathrm{t}(6)=4.76, \mathrm{p}<.01]$. 